\title{
Media-Portrayed Idealized Images, Body Shame, and Appearance Anxiety
}

\author{
Fiona Monro, B Psychology (Hons) \\ Gail Huon, PhD*
}

\begin{abstract}
Objective: This study was designed to determine the effects of media-portrayed idealized images on young women's body shame and appearance anxiety, and to establish whether the effects depend on advertisement type and on participant self-objectification.
\end{abstract}

Method: Participants were 39 female university students. Twenty-four magazine advertisements comprised 12 body-related and 12 non-body-related products, one half of each with, and the other one half without, idealized images. Preexposure and post exposure body shame and appearance anxiety measures were recorded.

Results: Appearance anxiety increased after viewing advertisements featuring idealized images. There was also a significant interaction between selfobjectification level and idealized body (presence vs. absence). No differences emerged for body-related compared with non-body-related product advertisements. The only result for body shame was a main effect for time. Participants' body shame increased after exposure to idealized images, irrespective of advertisement type.

Discussion: Although our findings reveal that media-portrayed idealized images detrimentally affect the body image of young women, they highlight the individual differences in vulnerability and the different effects for different components of body image. These results are discussed in terms of their implications for the prevention and early intervention of body image and dieting-related disorders. (c) 2005 by Wiley Periodicals, Inc.

Keywords: appearance anxiety; body image; body shame; idealized images; self-objectification

(Int J Eat Disord 2005; 38:85-90)

\section{Introduction}

Western women are encouraged to achieve an idealized body shape that is tubular and thin (Groesz, Levine, \& Murnen, 2002; Guillen \& Barr, 1994). Media-portrayed images, especially those presented in the context of advertisements for dieting and weight-altering products, promote the idea that body shape and size are flexible, and that achieving the thin ideal is relatively easy (Brownell, 1991). The media images appear realistic, despite their heavy editing and refining with computer software (Richins, 1991; Thompson \& Heinberg, 1999). So, the mass media are generally agreed to be an influential source of images and messages about the idealized body that women and girls are expected to strive for (e.g., Anderson \& DiDomenico,

Accepted 21 June 2004

School of Psychology, University of New South Wales, Sydney, Australia

*Correspondence to: Professor Gail Huon, MD, School of Psychology, University of New South Wales, Sydney, NSW, 2052, Australia. E-mail: G.Huon@unsw.edu.au

Published online 21 June 2005 in Wiley InterScience

(www.interscience.wiley.com). DOI: 10.1002/eat.20153

(C) 2005 Wiley Periodicals, Inc.
1992; Botta, 1999; Field, Camargo, Taylor, Berkey, \& Colditz, 1999).

Some researchers have found strong positive correlations between the frequency with which adolescent girls read magazine dieting articles and their desire to change their body weight and shape (e.g., Field et al., 1999; Utter, Neumark-Sztainer, Wall, \& Story, 2003). Others have shown that television viewing is associated with body dissatisfaction (Botta, 1999; Field et al., 2001; Harrison \& Cantor, 1997), although the correlation appears to hold only for specific program and article types. Tiggemann and Pickering (1996) found, for example, that the viewing of serials and soap operas was associated with body dissatisfaction, and watching music video clips was related to drive for thinness. However, overall television viewing was not related to body dissatisfaction, perceived weight, or drive for thinness. In other words, there is some evidence that exposure to media-portrayed idealized images is associated with negative feelings about the body, and with the desire to alter its weight and shape. From correlational studies, however, we cannot be sure about the direction of the effect.

Some researchers have, therefore, compared the effects of exposure to thin ideal media images with 
a control condition in which no idealized body was present. For example, Turner, Hamilton, Jacobs, Angood, and Hovde (1997) showed that after viewing magazine images, body dissatisfaction was greater in the experimental than in the control condition, and Lavine, Sweeney, and Wagner (1999) showed a similar result for viewing television images. However, neither study included baseline measures to establish the impact of exposure with some certainty. In contrast, Cattarin, Thompson, Thomas, and Williams (2000) and Pinhas, Toner, Ali, Garfinkel, and Stuckless (1999) measured female students' body dissatisfaction and mood both before and after exposure to idealized magazine or television images. Those authors found that the increase in body dissatisfaction and negative mood from before to after viewing was greater in the experimental than in the control group.

Yet, it is unlikely that all young women are affected by idealized images to the same degree. Women who are more likely to be vulnerable are those whose attention is focused on appearance. According to Fredrickson and Roberts (1997), some women are more likely than others to see the self from the point of view of an outsider, and to regard their body as an object of other people's gaze. The authors coined the term self-objectification to characterize the tendency to value appearance over and above ability or any other attributes (Fredrickson \& Roberts, 1997). Such focus on appearance is believed to result in increased body shame and appearance anxiety, especially in conditions where the body is subjected to scrutiny (Fredrickson \& Roberts, 1997; McKinley \& Hyde, 1996). Exposure to media-portrayed idealized images focuses attention on the body, and encourages scrutiny of the acceptability of its shape and size (Kilbourne, 1994; Myers \& Biocca, 1992).

The focus of attention on the idealized images in some advertisements is direct. Thin idealized bodies are used to persuade women to buy products that help to improve the appearance of their body. In others, it is indirect. Idealized body images are also used to persuade people to buy non-bodyrelated products. An important research question is this: Are the effects of the direct and indirect focus on idealized bodies the same? Idealized images associated with products that are designed to alter the body, for example, through dieting or exercise, focus attention explicitly on its unacceptability. They might be expected, therefore, to affect feelings of body shame and appearance anxiety to a greater extent than advertisements that simply exploit the use of idealized body images for non-body-related products.
This study was concerned with the effects on young women's body shame and appearance anxiety of exposure to media-portrayed idealized images. We sought to determine the effects of exposure not only to advertisements with and without the presence of an idealized body, but importantly, of exposure to idealized bodies in the contexts of body-related and non-body-related advertisements. We also believed it important to establish whether the effects would be different for women who differ in their level of self-objectification.

We predicted that, when compared with images that do not feature idealized bodies, exposure to idealized bodies would result in increased body shame and appearance anxiety. We also expected that the effect would be more pronounced for body-related products, and for high self-objectifiers.

\section{Method}

\section{Overview and Design}

This experiment was concerned with the effects of exposure to idealized body magazine images on young women's body shame and appearance anxiety. The focus was on whether high self-objectifiers would respond differently than low self-objectifiers. Further, it was examined whether the effects would be different for bodyrelated and non-body-related product advertising images. Thus, the experiment involved a $2 \times(2) \times(2)$ factorial design. The first factor was self-objectification level (high vs. low), the second factor was advertisement type (body-related vs. non-body-related), and the third was idealized body (present vs. absent). The dependent measures tested in the analysis of variance (ANOVA) were body shame and appearance post-pre difference scores.

\section{Participants}

Thirty-nine women 17-37 years old participated in this experiment. They included psychology students $(n=28)$ who participated in exchange for course credit, and other college students who volunteered to be involved to learn about psychological research $(n=11)$.

\section{Materials}

The materials used in this study included pretest measures, experimental stimuli, and dependent measures.

Pretest Measures. Questionnaires were used to provide baseline measures for restraint status, appearance anxiety, body shame, self-objectification, self-monitoring, 
and exposure to magazines. The Restraint Questionnaire (RQ; Herman \& Polivy, 1975) was used to assess the extent to which participants are attitudinally and behaviorally concerned with their weight and dieting. The 12-item Social Physique/Appearance Anxiety Scale (SPAS; Hart, Leary \& Rejeski, 1989), which assesses how anxious participants feel when their bodies are observed or evaluated by others, was used to measure appearance anxiety in this experiment. Participants responded to each question on a 5-point scale from definitely disagree to definitely agree. This scale has high reliability $(\alpha=.90)$ and good construct validity $(r=.50)$ (Hart et al., 1989). A total score was calculated by summing responses. Total scores range from 12 to 60 , with high scores indicating a high level of appearance anxiety. The eight-item Body Shame subscale of the Objectified Body Consciousness Scale (BS-OBCS; McKinley \& Hyde, 1996) indicates how ashamed participants are of their body, and the extent to which participants have internalized the cultural thin ideal. Scores on this scale range from 8 to 14 , with high scores indicating a higher level of body shame. The eight-item Surveillance subscale of the Objectified Body Consciousness Scale (S-OBCS; McKinley \& Hyde, 1996) assesses the extent to which an individual monitors her appearance and views her body as if an observer. Possible scores on this scale range from 8 to 40 . High levels of self-monitoring (surveillance) manifest as high scores on this scale. The Self-Objectification Questionnaire (SOQ; Fredrickson, Roberts, Noll, Quinn, \& Twenge, 1998) was used to assess self-objectification in this study. This scale requires participants to rank a series of statements regarding the importance that they place on appearance and abilities on a scale from 0 to 9 . A self-objectification score is obtained by subtracting the ranks assigned to ability statements from the ranks assigned to appearance statements so that possible scores on this scale range from -25 to 25 .

Pretest scales to provide baseline measures were also obtained for appearance anxiety, body shame, and selfmonitoring using visual analog scales (VAS).

Experimental Stimuli. Twenty-four images were selected from popular magazines (e.g., Cleo, Cosmopolitan, Men's Health, Who Weekly). Twelve images were advertisements for body-related products, and 12 were advertisements for non-body-related products. Within each of these advertisement types, one half of the advertisements featured idealized bodies. The other one half were produced using computer manipulation via Adobe Photoshop (version 7.0; Adobe Systems, San Diego, CA), that is, they were the same, without the body in the image.

Dependent Measures. Experimental measures consisted of VAS for self-monitoring, appearance anxiety, and body shame. These were the same as the pretest measure VAS.
Body shame and appearance anxiety difference scores were obtained by subtracting the initial VAS score on that measure from the postexposure score.

A free recall memory test of the advertisements that the participants had viewed was used to ensure processing of the images and to enhance the cover story.

\section{Procedure}

This experiment was conducted in small groups. Participation took approximately $1 \mathrm{hr}$. This study was conducted in two sessions. Baseline data were collected in the initial session, and the experimental manipulation was conducted in the second session.

In the initial session, the experiment was presented to participants as an experiment investigating the effects of personality variables on the emotional experience of, and memory for, magazine advertisements, and participants completed consent forms and pretest measures as described earlier in the text.

In the second session, participants viewed 24 magazine advertisements, four blocks each of six idealized body present body-related product advertisements, idealized body absent body-related product advertisements, idealized body absent non-body-related product advertisements, and idealized body absent non-body-related product advertisements. Their order was counterbalanced. Participants were instructed that they would have $20 \mathrm{~s}$ to look at each advertisement, and that they should study the advertisements carefully and take in as much information as possible. At the end of each block of advertisements, participants were required to complete VAS assessing appearance anxiety and body shame. After viewing all the advertisements, and completing all the VAS, participants were given the free recall memory test.

Finally, participants were asked what they believed the aims of the study were, and then fully debriefed about the experiment. Their age, weight, and height details were also recorded at this time.

\section{Results}

\section{Participant Characteristics}

Participants' self-objectification level was determined according to their score on the SOQ (Fredrickson et al., 1998). Two participants were excluded because of incomplete data. Thus, the final sample of participants was 37 women comprising 18 low self-objectifiers and 19 high selfobjectifiers. The mean self-objectification scores for the low and high self-objectifying groups were -10.88 and 8.26 , respectively. The difference between those means was significant $(F=49.6$, $\left.F_{c}=F_{0.05 ; 1,36}=4.113\right)$. The means for age, weight, 
height, body mass index (BMI), number of magazines read, and time spent reading magazines for both the high and low self-objectifying groups are presented in Table 1. Table 1 shows that there were no other significant differences between the low and high self-objectifiers.

\section{Effects of Idealized Body Exposure}

The post-pre exposure difference scores were calculated for all participants, for all experimental conditions. Table 2 presents the means and standard deviations for those scores, separately for low and high self-objectifiers.

Body Shame. Table 2 shows that participants experienced less body shame after exposure to images without idealized bodies. This was the case for both non-body-related product and body-related product advertisements. However, after exposure to advertisements containing idealized bodies (non-body-related and body-related product advertisements), their body shame was greater. This pattern of results occurred for both the high and low self-objectifiers. Thus, the main effect for idealized body condition was significant $\left(F_{1,35}=\right.$ 5.77; $\left.F_{c}=F_{0.05 ;}, 1,35=4.12\right)$. However, the selfobjectification main effect, the advertisement type main effect, and the interactions were not significant.

Appearance Anxiety. There was a significant main effect for idealized body condition $\left(F_{1,35}=14.368\right.$; $\left.F_{c}=F_{0.05 ; 1,35}=4.12\right)$. That is, irrespective of selfobjectification level or advertisement type, participants experienced less appearance anxiety after exposure to advertisements without an idealized body, and greater appearance anxiety after viewing advertisements featuring an idealized body.

The salient pattern of results in Table 2, however, is the significant two-way interaction between selfobjectification level and idealized body condition (presence vs. absence) $\left(F=5.83 ; F_{0.05 / 2 ; 1,35}=5.485\right)$. To facilitate interpretation, this interaction is represented graphically in Figure 1.

The difference in appearance anxiety between body present and body absent conditions was greater for high self-objectifiers than for low selfobjectifiers. High self-objectifiers experienced markedly greater appearance anxiety in the body present condition than the body absent condition, whereas low self-objectifiers' appearance anxiety was only slightly higher in the body present condition than in the body absent condition. There were no other significant interaction effects.

TABLE 1. Means and standard deviations for age, weight, height, BMI, number of magazines read, and time spent reading magazines, showing the similarities between the low and the high self-objectification groups

\begin{tabular}{|c|c|c|c|c|c|c|c|c|}
\hline & \multicolumn{8}{|c|}{ Self-Objectification Level } \\
\hline & \multicolumn{2}{|c|}{ Total $(n=37)$} & \multicolumn{2}{|c|}{ Low $(n=18)$} & \multicolumn{2}{|c|}{ High $(n=19)$} & \multirow[b]{2}{*}{$F$} & \multirow[b]{2}{*}{$P$} \\
\hline & $M$ & $S D$ & $M$ & $S D$ & $M$ & $S D$ & & \\
\hline Age & 19.68 & 3.23 & 20.22 & 4.49 & 19.16 & 1.07 & 1.01 & .32 \\
\hline Weight & 58.84 & 9.36 & 60.53 & 10.22 & 57.24 & 8.42 & 1.15 & .29 \\
\hline Height & 1.65 & 0.09 & 1.67 & 0.10 & 1.63 & 0.08 & 1.73 & .20 \\
\hline BMI & 21.61 & 2.68 & 21.68 & 2.75 & 21.54 & 2.69 & 0.27 & .87 \\
\hline Magno $^{\mathrm{a}}$ & 2.24 & 1.40 & 2.33 & 1.81 & 2.16 & 0.90 & 0.14 & .71 \\
\hline Magexp ${ }^{b}$ & 3.43 & 2.78 & 2.78 & 2.70 & 4.05 & 2.80 & 1.99 & .17 \\
\hline
\end{tabular}

Note: $\mathrm{BMI}=$ body mass index.

${ }^{a}$ Number of magazines read per month.

${ }^{\mathrm{b}}$ Hours per month spent reading magazines.

TABLE 2. Means and standard deviations of body shame and appearance anxiety, after exposure to each of the magazine advertisement conditions, for low and high self-objectifying women

\begin{tabular}{|c|c|c|c|c|c|c|c|c|c|c|c|c|c|c|c|c|}
\hline & \multicolumn{8}{|c|}{ Low Self-Objectifiers $(n=18)$} & \multicolumn{8}{|c|}{ High Self-Objectifiers $(n=19)$} \\
\hline & \multicolumn{4}{|c|}{ Idealized Body Absent } & \multicolumn{4}{|c|}{ Idealized Body Present } & \multicolumn{4}{|c|}{ Idealized Body Absent } & \multicolumn{4}{|c|}{ Idealized Body Present } \\
\hline & \multicolumn{2}{|c|}{ Nonbody Ads } & \multicolumn{2}{|c|}{ Body Ads } & \multicolumn{2}{|c|}{ Nonbody Ads } & \multicolumn{2}{|c|}{ Body Ads } & \multicolumn{2}{|c|}{ Nonbody Ads } & \multicolumn{2}{|c|}{ Body Ads } & \multicolumn{2}{|c|}{ Nonbody Ads } & \multicolumn{2}{|c|}{ Body Ads } \\
\hline & $M$ & $S D$ & $M$ & $S D$ & $M$ & $S D$ & $M$ & $S D$ & M & $S D$ & $M$ & $S D$ & $M$ & $S D$ & $M$ & $S D$ \\
\hline Body shame ${ }^{a}$ & -3.08 & 19.75 & -1.12 & 18.37 & 1.52 & 24.26 & 2.77 & 21.94 & -5.03 & 19.47 & 6.16 & 23.59 & 8.03 & 17.01 & 7.02 & 19.33 \\
\hline Appearance anxiety ${ }^{b}$ & -9.78 & 21.62 & -4.75 & 21.97 & -0.15 & 22.88 & -4.90 & 29.85 & -5.89 & 27.51 & -0.05 & 24.89 & 9.45 & 27.12 & 11.76 & 21.16 \\
\hline
\end{tabular}

Note: Ads = advertisements.

${ }^{a}$ Body shame deviation score (post-pre).

${ }^{\mathrm{b}}$ Appearance anxiety deviation score (post-pre). 
FIGURE 1. Significant interaction between selfobjectification level and idealized body for appearance anxiety difference scores. Diamonds $=$ low selfobjectification; squares $=$ high self-objectification.

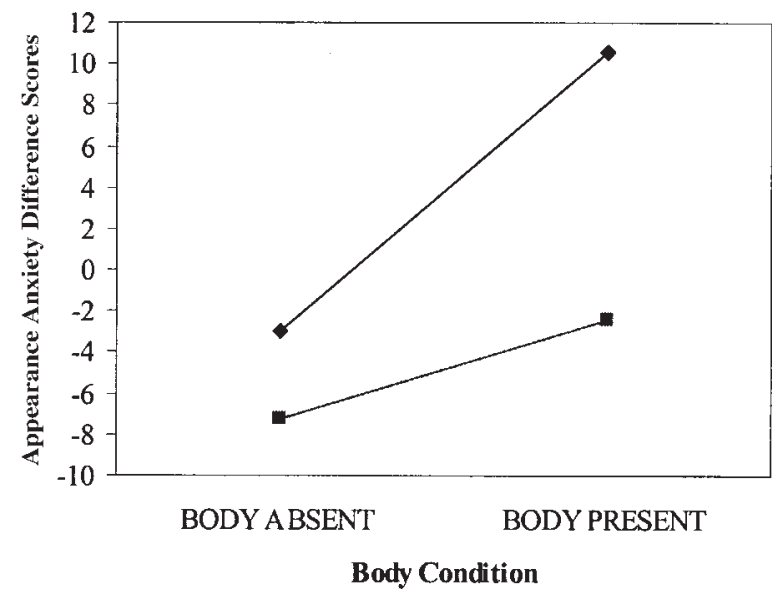

Contrary to our prediction, there was no main effect for advertisement type. Nor did advertisement type interact with the other factors.

\section{Discussion}

This study investigated the effect of exposure to media-portrayed idealized images on the body shame and appearance anxiety of young women, and tested whether these effects differed for high and low self-objectifiers. Further, we were interested to see whether body-related product advertisements were more likely to affect women's body shame and appearance anxiety than non-bodyrelated product advertisements.

We found that exposure to idealized images led to increased body shame and appearance anxiety. As we predicted, the effects of such exposure on appearance anxiety were greater for high selfobjectifiers. High self-objectifiers showed a marked increase in appearance anxiety after exposure to idealized images, whereas low self-objectifiers showed a small increase.

In contrast, there was no significant difference in the postexposure feelings of body shame among high and low self-objectifiers. This lack of difference for the self-objectification groups was unexpected and inconsistent with previous research (Fredrickson et al., 1998; Gapinski, Brownell, \& LaFrance, 2003).

It is unlikely that the VAS did not detect transient changes, given the support for the use of the VAS (e.g., Heinberg \& Thompson, 1995; Lavin \& Cash, 2000). It is also unlikely that insufficient power can explain the lack of an effect. Thus, data would seem to suggest that the impact of self-objectification on changes in body shame is confined to situations in which the participants were wearing little clothing. Perhaps the effect outlined by Fredrickson et al. (1998) and Gapinski et al. (2003) does not extend to viewing idealized images.

Another unexpected finding was the lack of main or interaction effects for advertisement type. Lockwood and Kunda (1997) proposed that selfview and behavior are more likely to be influenced by role models that make the goal appear attainable and relevant. We expected, therefore, that bodyrelated product advertisements, through their specific reference to the thin ideal and methods to lose weight, would be more likely to affect body image than non-body-related product advertisements. Further, as the thin ideal is especially salient for high self-objectifiers, it was expected that the effects would be greater for these individuals. Despite these results, the inclusion of an explicit comparison between body-related and non-body-related advertisements was an important feature of our study that goes beyond existing research in this field. As participants were explicitly instructed to study the advertisements in preparation for a future memory test, it is unlikely that participants did not explicitly focus on the idealized bodies. It is possible that the advertisements were not perceived in such a way that made the thin ideal more attainable or relevant. Our current work is assessing the salience, relevance, and attainability of the images to determine the importance of these judgments.

An additional strength of our study was the use of carefully controlled stimuli. The stimuli in the two advertisement conditions were identical, apart from the presence or absence of an idealized body. As a pretest/posttest design with random allocation to exposure conditions was used, changes in body shame and appearance anxiety could be attributed confidently to the manipulation. However, only immediate effects of exposure were recorded. Our work is also seeking to establish the duration of such effects.

The current study provides further support for sociocultural determinants of body image and eating disturbance. Idealized images are an influential source of pressure to meet the thin ideal. However, such images are not equally detrimental to all young women. Self-objectification increases the risk of being negatively affected by idealized images. Piran (2002) argues that the variable success of prevention programs is attributable to the lack of focus on prospective risk factors. The findings from our study highlight such a risk factor. 
Recent critical reviews (e.g., Groesz et al., 2002; Pearson, Goldklang, \& Streigal-Moore, 2002) urge researchers to carry out well-controlled experiments to shed light on the impact of media on body image and eating behaviors. We have provided an important step towards that goal.

\section{References}

Anderson, A.E., \& DiDomenico, L. (1992). Diet vs. shape content of popular male and female magazines: A dose-response relationship to the incidence of eating disorders? International Journal of Eating Disorders, 11(3), 283-287.

Botta, R.A. (1999). Television images and adolescent girls' body image disturbance. Journal of Communication, 49(2), 22-40.

Brownell, K.D. (1991). Dieting and the search for the perfect body: Where physiology and culture collide. Behavior Therapy, 22, 1-12.

Cattarin, J.A., Thompson, J.K., Thomas, C., \& Williams, R. (2000). Body image, mood, and televised images of attractiveness: The role of social comparison. Journal of Social and Clinical Psychology, 19, 220-239.

Field, A.E., Camargo, C.A., Taylor, C.B., Berkey, C.S., \& Colditz, G.A. (1999). Relation of peer and media influences to the development of purging behaviors among preadolescents and adolescents. Archives of Pediatric and Adolescent Medicine, 153, 1184-1189.

Field, A.E., Camargo, C.A., Taylor, C.B., Berkey, C.S., Roberts, S.B., \& Colditz, G.A. (2001). Peer, parent, and media influences in the development of weight concerns and frequent dieting among preadolescent and adolescent girls and boys. Pediatrics, 107(1), 54-60.

Fredrickson, B.L., \& Roberts, T. (1997). Objectification theory: Toward understanding women's lived experiences and mental health risks. Psychology of Women Quarterly, 21, 173-206.

Fredrickson, B.L., Roberts, T., Noll, S.M., Quinn, D.M., \& Twenge, J.M. (1998). That swimsuit becomes you: Sex differences in selfobjectification, restrained eating, and math performance. Journal of Personality and Social Psychology, 75(1), 269-284.

Gapinski, K.D., Brownell, K.D., \& LaFrance, M. (2003). Body objectification and "fat talk": Effects on emotion, motivation, and cognitive performance. Sex Roles, 48(9-10), 377-388.

Groesz, L.M., Levine, M.P., \& Murnen, S.K. (2002). The effect of experimental presentation of thin media images on body satisfaction: A meta-analytic review. International Journal of Eating Disorders, 31(1), 1-16.

Guillen, E.O., \& Barr, S.I. (1994). Nutrition, dieting, and fitness messages in a magazine for adolescent women, 1970-1990. Journal of Adolescent Health, 15, 464-472.

Harrison, K., \& Cantor, J. (1997). The relationship between media consumption and eating disorders. Journal of Communication, 47(1), 40-67.
Hart, E.A., Leary, M.A., \& Rejeski, W.J. (1989). The measurement of social physique anxiety. Journal of Sport and Exercise Psychology, 11, 94-104.

Heinberg, L.J., \& Thompson, J.K. (1995). Body image and televised images of thinness and attractiveness. Journal of Social and Clinical Psychology, 14, 325-338.

Herman, C.P., \& Polivy, J. (1975). Anxiety, restraint and eating behavior. Journal of Abnormal Psychology, 84(6), 666-672.

Kilbourne, J. (1994). Still killing us softly: Advertising and the obsession with thinness. In P. Fallon, M.A. Katzman, \& S.C. Wooley (Eds.), Feminist perspectives in eating disorders (pp. 395-418). New York: Guilford Press.

Lavin, M.A., \& Cash, T.F. (2000). Effects of exposure to information about appearance stereotyping and discrimination on women's body images. International Journal of Eating Disorders, 29, 51-58.

Lavine, H., Sweeney, D., \& Wagner, S. H. (1999). Depicting women as sex objects in television advertising: Affects of body dissatisfaction. Personality and Social Psychology Bulletin, 25(8), 1049-1058.

Lockwood, P., \& Kunda, Z. (1997). Superstars and me: Predicting the impact of role models on the self. Journal of Personality and Social Psychology, 73(1), 91-103.

McKinley, N.M., \& Hyde, J.S. (1996). The Objectified Body Consciousness Scale. Psychology of Women Quarterly, 20, 181-215.

Myers, P.N., \& Biocca, F.A. (1992). The elastic body image: The effect of television advertising and programming on body image distortions in young women. Journal of Communication, 42(3), 108-133.

Pearson, J., Goldklang, D., \& Striegel-Moore, R.H. (2002). Prevention of eating disorders: Challenges and opportunities. International Journal of Eating Disorders, 31, 233-239.

Pinhas, L., Toner, B.B., Ali, A., Garfinkel, P.E., \& Stuckless, N. (1999). The effects of the ideal of female beauty on mood and body satisfaction. International Journal of Eating Disorders, 25(2), 223-226.

Piran, N. (2002). Prevention of eating disorders. In C.G. Fairburn \& K.D. Brownell (Eds.), Eating disorders and obesity: A comprehensive handbook (2nd ed., pp. 367-371). New York: Guilford Press.

Richins, M.L. (1991). Social comparison and the idealized images of advertising. Journal of Consumer Research, 18, 71-83.

Thompson, J.K., \& Heinberg, L.J. (1999). The media's influence on body image disturbance and eating disorders: We've reviled them, now can we rehabilitate them? Journal of Social Issues, 55, 339-353.

Tiggemann, M., \& Pickering, S. (1996). Role of television in adolescent women's body dissatisfaction and drive for thinness. International Journal of Eating Disorders, 20(2), 199-203.

Turner, S.L., Hamilton, H., Jacobs, M., Angood, L.M., \& Hovde, D.D. (1997). The influence of fashion magazines on the body image satisfaction of college women: An exploratory analysis. Adolescence, 32(17), 603-614.

Utter, J., Neumark-Sztainer, D., Wall, M., \& Story, M. (2003). Reading magazine articles about dieting and associated weight control behaviors among adolescents. Journal of Adolescent Health, 32, 78-82. 